\title{
Inherited Bone Marrow Failure Syndrome
}

National Cancer Institute

\section{Source}

National Cancer Institute. Inherited Bone Marrow Failure Syndrome. NCI Thesaurus. Code C94810.

A group of inherited genetic hematopoietic stem cell disorders characterized by bone marrow failure that involves one or more cell lines. Representative examples include Fanconi anemia, Diamond-Blackfan anemia, and Shwachman-Diamond syndrome. 